\title{
ECUMENICAL HERMENEUTICS
}

\author{
Eklepinus Jefry Sopacuaperu
}

Mahasiswa PascasarjanaTeologi UKDW Yogyakarta

Email: eklepinusjefry@gmail.com

\begin{abstract}
This paper is a brief introduction and an explanation about the terms "ecumenical hermeneutics", its essential principles and its possible relevancesto the ecumenical context of Indonesia. As an introduction, the explanation is written as simple as possible with numerous purposes. Firstly, it is to be easily understood by the readers who are newly introduced to the issue and terminology of "ecumenical hermeneutics". Secondly,it is meant to open a new space to academic literacy and theological discourse about the issue of ecumenical nowadays, as well as to provide a new paradigm in developing ecumenical movement in Indonesia.
\end{abstract}

Keywords: Ecumenical Hermeneutics, Ecumenical Movement, New Paradigm, Theological Discourse

\begin{abstract}
Abstrak
Tulisan ini dimaksudkan untuk memberi pengantar dan uraian singkat mengenai apa itu "ecumenical hermeneutics" bagaimana prinsip-prinsip esensialnya dan kemungkinan relevansinya dalam konteks ekumene di Indonesia. Karena sifatnya sebagai pengantar, maka uraiannya dibuat sesederhana mungkin, dengan beberapa tujuan. Pertama, supaya mudah dipahami oleh mereke, yang baru terhadap isu dan terminologi "ecumenical hermeneutics" Kedua, membuka ruang baru bagi literasi akademis dan diskursus teologis mengenai isu ekumene dewasa ini, serta diharapakan dapat menjadi salah satu paradigma baru dalam pengembangan gerakan ekumene di Indonesia.
\end{abstract}

Kata kunci: Ecumenical Hermeneutics, Gerakan Ekumene, Paradigma Baru, Diskursus Teologis

\section{PENGANTAR}

Tulisan mengenai "Ecumenical Hermeneutics" menjadi pilihan dalam kajian ini disebabkan oleh rasa kecintaan yang dalam terhadap dunia "hermeneutik" dan ketertarikan (interest) terhadap terminologi Ecumenical Hermeneutics. Diskursus mengenai Ecumenical Hermeneutics sebetulnya lahir dari pertanyaan-pertanyaan 
hermeneutis (hermeneutical questions), kegelisahan hermeneutis, dan berbagai perbedaan penafsiran yang muncul terhadap dokumen BEM. Respon terhadap berbagai persoalan itu dirumuskan dalam dokumen Faith and Order (No. 182/1998) dengan judul "A Treasure in Earthen Vessels: An Instrument for an Ecumenical Reflection on Hermeneutics." Oleh sebab itu, pembahasan mengenai Ecumenical Hermeneutics akan memperhatikan dokumen Faith and Order sebagai salah satu bagian penting.

Kenyataan bahwa keragaman denominasi gereja-gereja (multiplicity of church denomination) serta kelompok-kelompok misi menjadi salah satu tantangan bagi gerakan ekumenisme di Asia. ${ }^{1}$ Tantangan yang menonjol dari realitas ini ialah bagaimana membangun dialog ekumenis diantara keragaman denominasi, cara pandang, pendekatan atau gaya berteologi, bahkan pemahaman penafsiran (interpretation) yang beragam, serta perbedaan corak satu sama lain. ${ }^{2}$ Tidak hanya pada level global (Asia), keberagaman corak berteologi (hermeneutis) juga mengakibatkan terhambatnya dialog serta relasi ekumenis diantara denominasidenominasi gereja di tingkat nasional bahkan lokal. Karena itu, pembahasan mengenai Ecumenical Hermeneutics sangat penting sebagai salah satu jalan (the way) untuk mendorong dan memotivasi terbentuknya dialog ekumenis di tengah keragaman denominasi gereja yang ada.

\section{PERGESERAN PARADIGMA DALAM GERAKAN EKUMENE}

C. S. Song mengungkapkan bahwa paradigma telah mengalami pergeseran dari utara ke selatan, barat ke timur, top to bottom, bahkan bergerak ke arah ortopraxis dan tidak berhenti pada ortodoxy. Baginya, masa depan ekumenisme ditentukan melalui bagaimana kita memahami posisi selatan dan timur, memposisikan diri, memulai gerakan bersama dari bawah (find our place at the bottom), berkomitmen pada ortopraxis dan menjadikan gerakan ekumenis sebagai gerakan solidaritas bersama dengan mereka yang menderita, miskin dan termarginalkan. ${ }^{3}$ Pergeseran paradigma turut membaharui komitmen ekumenis dan menjadikan ekumene sebagai gerakan yang bermuara pada hidup bersama. ${ }^{4}$

Senada dengan Song, Longchar melihat konteks global(isasi) saat ini sebagai salah satu pendorong utama pentingnya pergeseran paradigma (paradigm shift) dalam gerakan ekumene. Bahkan, Longchar menegaskan perlunya paradigma baru 
(new paradigm) dalam menyikapi realitas konteks yang ada saat ini. ${ }^{5}$ Sedangkan, Shastri secara tajam mengungkapkan bahwa pergeseran paradigma dalam gerakan ekumene telah menonjolkan dua pergeseran paradigma yang salah satunya berupa meluasnya horizon ekumene yang melampaui komunitas Kristiani menuju kepada seluruh makhluk. ${ }^{6}$ Shastri hendak menegaskan bahwa pergeseran paradigma ini tidak hanya menjadikan gerakan ekuemenis sebagai sebuah gerakan Kekristenan atau yang berorientasi pada Kekristenan saja sehingga terkesan sempit dan eksklusif. Sebaliknya, pergeseran paradigma menjadikan gerakan ekumene lebih luas dan melampaui Kekristenan itu sendiri serta menyapa seluruh makhluk.

Pegeseran paradigma dalam gerakan ekumenis juga dituliskan oleh Hope S. Antone yang melihat tentang tantangan berekumene di Asia dan pentingnya perubahan paradigma dalam gerakan ekumene. Sebagai bagian dari gereja-gereja di Asia, gagasan yang dikemukakan oleh Antone juga penting untuk dicermati oleh gereja-gereja di Indonesia dalam usaha untuk menghidupi gerakan ekumenis yang ada. Pergeseran paradigma itu antara lain: pertama, pergeseran dari kompetisi kepada kerjasama (from competition to cooperation) diantara denominasi gerejagereja yang ada. Baginya, jiwayang seharusnya mewarnai gerakan ekumenis bukanlah rivalitas melainkan kerjasama. Kedua, pergeseran dari perilaku saling menyalahkan ke tindakan dialog bersama. Ketiga, keluar dari keterisolasian, eksklusifisme, dan ketertutupan menuju kepada keterbukaan dalam kolaborasi bersama antar denominasi gereja-gereja. Keempat, bergerak dari disintegrasi kepada keutuhan ciptaan. Keempat pergeseran paradigma gerakan ekumenis ini menampakan cakupan gerakan ekumenis yang luas meliputi umat beragama lain (inter-religious) dan bahkan seluruh alam ciptaan (ecology).

Pergeseran paradigma dalam gerakan ekumene ini penting disebutkan di bagian awal tulisan ini sebab akan mewarnai keseluruhan ide yang akan dibangun dan memberi bentuk bagi pengembangan ide yang akan dilakukan. Karena itu,sangat penting untuk menegaskan pergeseran paradigma dalam gerakan ekumene sebelum membahas lebih jauh mengenai pokok persoalan yang hendak dikaji dalam tulisan ini. Penegasan pergeseran paradigma ini juga dimaksudkan untuk memberi bingkai pemahaman dan keselarasan dalam memahami gerakan ekumene dewasa ini. 


\section{ECUMENICAL HERMENEUTICS}

WCC melalui dokumen Faith and Order, No. 182/1998 dengan judul "A Treasure in

Earthen Vessels: An Instrument for an Ecumenical Reflection on

Hermeneutics", menjelaskan bahwa: ${ }^{7}$

Ecumenical hermeneutics shares with other forms of hermeneutics the goal of facilitating interpretation, communication and reception of texts, symbols and practices which give shape and meaning to particular communities. In recent years the definitions of hermeneutics have multiplied in philosophy and theology, and the scope of the term has been widened beyond giving principles for the interpretation of Holy Scripture. In this text we take the term hermeneutics to mean both; the art of interpretation and application of texts, symbols and practices in the present and from the past, and the theory about the methods of such interpretation and application.

More specifically, theological hermeneutics concerns itself with texts, symbols, and practices which have been inherited and shaped within a tradition of faith. For Christians this tradition of faith includes the Scriptures of the Old and the New Testaments and the expressions of the Christian faith transmitted and reexpressed through the centuries. Within theological hermeneutics, ecumenical hermeneutics serves the specific task of focusing on how texts, symbols and practices in the various churches may be interpreted, communicated and mutually received as the churches engage in dialogue. In this sense it is a hermeneutics for the unity of the Church.

Penjelasan defenitif di atas dirumuskan kembali oleh William Tabbernee secara sederhana namun tepat melalui rumusan bahwa: "Ecumenical hermeneutic is a way of understanding, interpreting and communicating the scriptures (and other texts) together." 8 Tabbernee melihat Ecumenical Hermeneutics sebagai cara memahami, mengerti dan mengkomunikasikan kitab suci (dan berbagai teks lainnya) secara bersama. Sebagaimana prinsip hermeneutik pada umumnya, Ecumenical Hermeneutics tidak berhenti pada aspek pemahaman dan penafsiran saja tetapi berlanjut pada aspek komunikasi. Aspek komunikasi itu memperlihatkan dimensi kontinuitas dan kolektifitas sebab ada gerak komunikasi secara bersama.

Aspek komunikasi dalam Ecumenical Hermeneutics lebih jauh dibahas oleh Ahram Kang yang mendefenisikan Ecumenical Hermeneutics dengan memberi tekanan pada budaya (culture). Kang mengatakan bahwa:Ecumenical Hermeneutic aims for unity through koinonia in diversity, and thus for mutual complement and learning through new understandings of the gospel interpreted in each culture. ${ }^{9}$ Melalui tekanan pada budaya, Kang sebetulnya hendak melihatEcumenical 
Hermeneutics dalam kesejajarannya dengan "cross-cultural hermeneutics" maupun "intercultural-hermeneutics". ${ }^{10}$ Bahkan, Kang dengan tegas mengatakan bahwa: Ecumenical Hermeneutic is rooted in intercultural hermeneutics. ${ }^{11}$

Sedangkan, pemahaman Sinners ${ }^{12}$ akanEcumenical Hermeneutics (E.H) yang juga dipengaruhi oleh dokumen Faith and Order, No. 182/1998,melihat E.H sebagai "an attempt to unviel the reasons for the apparent lack of agreement through the analysis of divergent ways of understanding Scripture and its tradition as well as for the difficulty of mutual understanding between Christians". Terdapat setidaknya dua hal penting yang hendak ditekankan oleh Sinner berkaitan dengan Ecumenical Hermeneutics, yaitu (1) analysis of the divergent atau menganalisis perbedaanperbedaan yang ada dalam memahami Kitab Suci (KS) maupun tradisi dan (2) bagaimana memiliki mutual understanding. Sejatinya,mutual understanding atau saling memahami satu sama lain merupakan persoalan yang sulit danEcumenical Hermeneutics membantu untuk dapat saling memahami, mengerti dan menerima satu sama lain.

Lebih jauh, Sinners melihat bagaimana teks Kitab Suci, simbol-simbol liturgis dan peribadatan, juga praksis beribadahan yang ada pada berbagai macam gereja itu dapat dilihat dan diinterpretasi bersama, untuk kemudian dikomunikasikan dalam sikap saling menerima satu sama lain sebagai gereja, serta untuk membangun dialog. ${ }^{13}$ Sinners dengan tegas melihat Ecumenical Hermeneutics tidak hanya sebatas melakukan interpretasi terhadap Kitab Suci, berbagai praksis liturgis serta tradisi yang beragam. Ia menegaskan bagaimana hal itu dikomunikasikan lebih jauh melalui sikap saling menerima satu sama lain, serta membangun dialog ekumenis yang lebih terbuka dan berkelanjutan.

Penjelasan yang lain mengenai Ecumenical Hermeneutics dikemukakan juga oleh Böttigheimer ${ }^{14}$ dalam artikelnya "ökumenische Hermeneutik: vom Theoriedefizit der ökumenischen bewegung”. Böttigheimer menyebutkan bahwa Ecumenical Hermeneutics tidak lain adalah hermeneutik untuk kesatuan atau keesaan gereja (Hermeneutik für die einheit der Kirche). ${ }^{15}$ Yang dimaksudkan dengan hermeneutik untuk keesaan gereja bukanlah hermeneutik yang hanya menekankan pada aspekaspek kesamaan untuk membangun kebersatuan gereja-gereja, melainkan hermeneutik yang berbasis juga pada pemahaman mengenai pluralitas atau keberagaman yang ada di dalam bahkan diantara gereja-gereja. Oleh karena itu, 
Böttigheimer memahami Ecumenical Hermeneutics juga sebagai hermeneutik pluralen Verstehens. ${ }^{16}$ Dalam kenyataan keberagaman gereja itulah Böttigheimer menekankan pemahamanEcumenical Hermeneutics sebagai bagian yang perlu diperhatikan secara serius. Böttigheimer menulis "einer ökumenischen hermeneutik dadurch zu respektieren und zu achten."17

Berbagai defenisi Ecumenical Hermeneutics yang telah dikemukakan sebetulnya saling berkaitan erat, serta memiliki cakupan makna dan pembahasan yang luas. Namun, kajian ini akan dibatasi pada defenisi yang disampaikan oleh WCC dan akan lebih banyak diterangi oleh pemikiran defenitif yang diutarakan oleh William Tabbernee dalam dialog dengan sejumlah pandangan yang dikemukakan sebelumnya.

\section{a. Prinsip-Prinsip dan Elemen Esensial dari Ecumenical Hermeneutics}

1. Ecumenical Hermeneutics lebih dari sekedar menafsirkan teks kitab suci di dalam konteks ekumenis.

Artinya,concern dari Ecumenical Hermeneutics bukan hanya tentang menafsirkan teks kitab suci, melainkan juga menafsirkan teks-teks lain seperti pengakuan iman, tulisan bapa-bapa gereja, dokumen-dokumen bersama yang dihasilkan antar-gereja (Joint Declaration), ensiklik-ensiklik, dan dokumendokumen gerejawi lainnya yang dihasilkan melalui dialog bilateral atau multilateral antar-gereja.

Hal ini dimungkinkan sebab penafsiran terhadap kitab suci tidak dapat dipisahkan dari penafsiran terhadap teks-teks lainnya yang relevan. Keduanya tidak harus di dikotomisasikan atau dipertentangkan. ${ }^{18}$ Böttigheimer dengan jelas menuliskan bahwa:

ökumenischen hermeneutik nicht nur auf eine gemeinsame Bibelinterpretation, sondern ebenso auf ein sachgemäßes Verstehen der eigenen wie der anderen konfession, ihres Galaubens, ihrer Bekenntnisse, Zeugnisse und Lehren wie auch ihrer konkreten Lebensäßerungen und spezifischen Traditionen, wie $\quad$ Symbole, Riten, und Bräuche. ${ }^{19}$

2. Ecumenical Hermeneutics memperhatikan secara serius peran tradisi dalam memahami dan menafsirkan Kitab Suci.

Di dalam Ecumenical Hermeneutics, relasi antara kitab suci dan tradisi diperhatikan secara serius untuk memperoleh makna yang dalam terhadap penafsiran yang dilakukan. Memisahkan antara bagian kitab suci dan tradisi di 
dalam Ecumenical Hermeneutics merupakan dikotomisasi yang keliru. Oleh karena Ecumenical Hermeneutics merupakan proses multidimensional, maka berbagai aspek termasuk tradisi menjadi penting untuk diperhatikan dalam menafsirkan dan memahami teks kitab suci. ${ }^{20}$

3. Ecumenical Hermeneutics bukan "comparative ecclesiology".

Oleh karena Ecumenical Hermeneutics menafsirkan teks kitab suci dan teks-teks lainnya seperti rumusan pengakuan iman secara bersama, maka tekanan terhadap dialog menjadi penting. Dengan kata lain,Ecumenical Hermeneuticssama seperti dialog ekumenis. Ecumenical Hermeneutics tidak bertanya tentang perbandingan eklesiologi diantara gereja-gereja untuk kemudian dipertentangkan satu sama lain. Ecumenical Hermeneuticsjuga bukanlah soal bagaimana menemukan kesalahan penafsiran teks kitab suci, doktrin, simbol-simbol dan praksis hidup yang berbeda dengan yang diyakini antara satu dan yang lainnya. Sebaliknya, Ecumenical Hermeneuticsberfokus pada usaha untuk dapat memahami dan menafsirkan kitab suci, doktrin, simbolsimbol dan praksis hidup gerejawi kendati pemahaman akan hal-hal tersebut berbeda. Dengan demikian, dapat dikatakan bahwa Ecumenical Hermeneutics melihat kepelbagaian eklesiologis secara dialogis dan bukan konfrontatif. ${ }^{21}$

4. Ecumenical Hermeneutics bersifat murah hati, ramah dan terbuka (openminded).

Ecumenical Hermeneuticsadalah tindakan hermeneutik dalam kemurahan hati dan keramah-tamahan. Murah hati dan ramah menjadi penting karena sejatinya tidak ada komunitas Kristen yang dengan absolut mengklaim bahwa seluruh praksis hidup kristiani dimiliki dan dilakukan secara utuh dan menyeluruh dalam suatu komunitas tertentu, sedangkan komunitas kristiani yang lain tidak. Murah hati dan ramah juga diperlukan karena tidak ada komunitas kristiani yang mengklaim secara absolut bahwa kebenaran iman Kristen hanya ada pada satu komunitas tertentu dan tidak dimiliki oleh komunitas kristiani lainnya.

Keramahan diwujudkan dalam sikap yang melampaui toleransi terhadap keragamanmenuju kepada sikap saling merangkul dalam perbedaan. Keramahan bahkan melihat dan merayakan keragaman itu secara bersama. Sedangkan, sifat 
open-mindeddikaitkan dengan lingkaran spiral hermeneutis yang berada dalam interaksi dialogis teks-konteks. ${ }^{22}$

5. Ecumenical Hermeneutics tidak dipahami sebagai ekumenisme Kristen yang terisolasi dari dialog dengan agama-agama lain (komunitas iman lainnya).

Salah satu tantangan utama dari gerakan ekumene di Asia ialah "kemajemukan agama" (religiusitas). ${ }^{23}$ Karena itu, Ecumenical Hermeneutics membuka dirinya terhadap dialog dengan agama-agama lain, serta tidak merasa dirinya sebagai yang superior atau unggul (triumphalistic) dari yang lain. Prinsip dialogis merupakan tekanan penting dalam Ecumenical Hermeneutics. Apabila superioritas Kristen ditekankan, maka dialog tidak akan berjalan dan hal itu berarti bahwa prinsip Ecumenical Hermeneutics tidak ada dalam tindakan semacam itu. ${ }^{24}$

6. Ecumenical Hermeneutics tidak memiliki satu priviledge terhadap satu metode interpretasi tertentu.

Karena Ecumenical Hermeneutics merangkul berbagai tradisi dan denominasi Kristiani dengan berbagai gaya dan nuansa tafsir serta metode interpretasi yang beragam, maka Ecumenical Hermeneutics tidak mengunggulkan satu metode tafsir tertentu dan memutlakannya sebagai satusatunya metode tafsir yang benar dan tepat. Sebaliknya, keragaman metode tafsir dan perspektif atau sudut pandang atau lensa penafsiran dipakai untuk memperkaya makna teks dalam membangun iman kristiani. Membaca Alkitab secara bersama-sama menjadi tujuan dari Ecumenical Hermeneutics. ${ }^{25}$

\section{b. Ecumenical Hermeneutics dan Gerakan Ekumene di Indonesia}

Hermeneutik memang bukan topik atau hal baru dalam gerakan ekumenis. Namun, perlu disadari bahwa kesadaran hermeneutik yang muncul hingga saat ini masih terbatas pada pemahaman kitab suci semata. Ulasan umum tentang Ecumenical Hermeneutics yang telah dilakukan sekilas memperlihatkan bahwa Ecumenical Hermeneutics penting dikembangkan dan dihidupi bersama dalam gerakan ekumenis. Aritonang mensinyalir beberapa agenda penting yang perlu disoroti oleh gerakan ekumene di Indonesia, yaitu mengenai hubungan dan dialog antar-agama, serta persoalan krisis lingkungan hidup yang semakin parah dan memprihatinkan. ${ }^{26}$ Ecumenical Hermeneutics memiliki cakupan yang luas, meliputi 
relasi antar-agama dan hubungan dengan alam semesta, yang dapat membantu mendorong untuk merespon hal-hal tersebut.

Umumnya, Ecumenical Hermeneutics dipahami hanya sebagai upaya yang berfokus pada pemahaman bersama mengenai kitab suci dan tradisi gereja. Namun, Ecumenical Hermeneutics sesungguhnya tidak berhenti pada hal itu saja, melainkan berlanjut untuk melihat dan meresponi kepelbagaian yang ada diantara gereja-gereja dengan keterbukaan dan sikap saling menghargai. ${ }^{27}$

Tidak dapat dipungkiri bahwa seringkali terjadi gap dalam relasi ekumenis diantara gereja-gereja yang mengakibatkan komunikasi ekumenis antar gereja tidak terjalin (dialog ekumenisnya macet). Apabila ditelusuri lebih jauh, maka salah satu penyebab macetnya dialog ekumenis ialah persoalan hermeneutik kitab suci, tradisi gereja, pengakuan iman, pola peribadatan, simbol-simbol liturgis dan paksis hidup bergereja lainnya yang berbeda, tidak saling dikenal atau dipahami. Oleh sebab itu, ulasan mengenai Ecumenical Hermeneutics penting untuk dikembangkan, dihidupi dalam semangat ekumenis bahkan diaktualisasikan. Hal ini dapat diawali dari para pimpinan gereja pada level sinodal, klasis dan jemaat-jemaat. Ecumenical Hermeneutics kemudian diteruskan dalam kehidupan berjemaat sebagai gerakan bersama dari bawah, sehingga gerakan ekumenis tidak hanya menjadi wacana para elit gereja maupun para akademisi/teolog, tetapi juga menjadi gerakan yang hidup pada level lokal sebagaimana ditegaskan oleh Kwok Nai Wang. ${ }^{28}$

Ecumenical Hermeneutics seyogianya dihidupi dan diaplikasikan dalam hidup berjemaat (bergereja) sebab gereja sesungguhnya adalah hermeneutical community $^{29}$ dan muara dari Ecumenical Hermeneutics ialah membangun persekutuan (growing koinonia) yang berkualitas. Dengan demikian, keyakinan saya senada dengan yang dikatakan oleh Rudolf Von Sinner bahwa: "I Strongly believe that an Ecumenical Hermeneutics could help us in Clarifying the points of covergence and divergence both across confessions and context. It could also help us establishing a procedure for common discernment, if needed and decision-making on theologies and practice of churches that seem to transgress the boundaries of the gospel." 30 


\section{Endnotes:}

${ }^{1}$ Mathews George Chunakara, "A Survey of Ecumenical Scenarion in Asia: Prospects and Challenges",CTC Bulletin, Vol. XXII, No. 2, Agustus (2006), 76

${ }^{2}$ Chunakara, "A Survey of Ecumenical Scenarion in Asia: Prospects and Challenges", 77

${ }^{3}$ C. S. Song, "The Ecumenical Calling of the Christian Church today: Ecumenism and ParadigmShifts",The Ecumenical Review, vol. 41 (1989), 254

${ }^{4}$ Song, "The Ecumenical Calling of the Christian Church today: Ecumenism and Paradigm-Shifts", 254-255

${ }^{5}$ A. Wati Longchar, "The Ecumenical Movement in Asia: A Theological Reflection",CTC Bulletin, Vol. XXII, No. 3,(2006), 49-51

${ }^{6}$ Hermen Shastri, "The Unity of the Church in a Changing World: An Asian Perspective", The Ecumenical Review, Vo. 66.No. 1, (2014), 26

${ }^{7}$ Lih,https://www.oikoumene.org/en/resources/documents/commissions/faith-and-order/ivinterpretation-the-meaning-of-our-words-and-symbols/a-treasure-in-earthen-vessels, poin ke-5

${ }^{8}$ William Tabbernee, "Interpreting the Scriptures Together Seeking the Visible Unity of the Church",Journal of Ecumenical Studies, Vol. 43, No. 3, (2008), 297

${ }^{9}$ Ahram Kang, "Ecumenical Hermeneutics through a study of Missiological Typologies", International Review of Mission, Vol. 104, No. 2, November (2015), 346

${ }^{10}$ Ahram Kang, "Ecumenical Hermeneutics through a study of Missiological Typologies", 351-352

${ }^{11}$ Ahram Kang, "Ecumenical Hermeneutics through a study of Missiological Typologies", 357

${ }^{12}$ Rudolf von Sinner, "Ecumenical Hermeneutics for a Plural Christianity and Chatolicity", Bangalore Theological Forum, vol. XXXIV, No. 2, (2002), 89

${ }^{13}$ Rudolf von Sinner, "Ecumenical Hermeneutics for a Plural Christianity and Chatolicity", 91

${ }^{14}$ Christoph Böttigheimer, "ökumenische Hermeneutik: vom Theoriedefizit der ökumenischen bewegung”,Stimmen Der Zeit, (2006), 392-406

${ }^{15}$ Christoph Böttigheimer, "ökumenische Hermeneutik”, 396

${ }^{16}$ Christoph Böttigheimer, "ökumenische Hermeneutik”, 397

${ }^{17}$ Christoph Böttigheimer, "ökumenische Hermeneutik", 397

${ }^{18}$ William Tabbernee, "Interpreting the Scriptures Together Seeking the Visible Unity of the Church", 298

${ }^{19}$ Christoph Böttigheimer, “ökumenische Hermeneutik”, 393

${ }^{20}$ William Tabbernee, "Interpreting the Scriptures Together Seeking the Visible Unity of the Church", 299-300

${ }^{21}$ William Tabbernee, "Interpreting the Scriptures Together Seeking the Visible Unity of the Church", 300-301

${ }^{22}$ William Tabbernee, "Interpreting the Scriptures Together Seeking the Visible Unity of the Church", 301

${ }^{23}$ Chunakara, "A Survey of Ecumenical Scenarion in Asia: Prospects and Challenges", 79

${ }^{24}$ William Tabbernee, "Interpreting the Scriptures Together Seeking the Visible Unity of the Church", h. 305

${ }^{25}$ William Tabbernee, "Interpreting the Scriptures Together Seeking the Visible Unity of the Church", h. 305

${ }^{26} \mathrm{Jan}$ S. Aritonang, "Current Ecumenical Movement and Spirit in Indonesia" dalam CTC Bulletin, vol. XXV, (2005), 31-38

${ }^{27}$ Peter Ben Smit, "The Meaning of LIFE: The Giving of Life as A Criterion for Ecumenical Hermeneutics", Journal of Ecumenical Studies, 43 (2008), 321-322

${ }^{28}$ Kwok Nai Wang, "Enchancing Ecumenism and the Ecumenical Movement at the Local Level", CTC Bulletin, vol. XXII, No. 2, (2006), 47-51

${ }^{29}$ Lih. Peter Bouteneff dan Dagmar Heller, (eds.), Interpreting Togther: Essays in Hermeneutics, (Geneva: WCC Publication, 2001), 136

${ }^{30}$ Sinner, "Ecumenical Hermeneutics: Suspicion vs. Coherence", 44-45 


\section{DAFTAR PUSTAKA}

Aritonang, Jan S. "Current Ecumenical Movement and Spirit in Indonesia" dalam CTC Bulletin, vol. XXV, April-August 2005.

Bouteneff, Peter dan Dagmar Heller, (eds.), Interpreting Togther: Essays in Hermeneutics, Geneva: WCC Publication, 2001.

Böttigheimer, Christoph, “ökumenische Hermeneutik: vom Theoriedefizit der ökumenischen bewegung” dalam Stimmen Der Zeit, Juni 2006.

Chunakara, Mathews George "A Survey of Ecumenical Scenarion in Asia: Prospects and Challenges" dalam CTC Bulletin, Vol. XXII, No. 2, Agustus 2006.

Kang, Ahram, "Ecumenical Hermeneutics through a study of Missiological Typologies" dalam International Review of Mission, Vol. 104, No. 2, November 2015.

Longchar, A. Wati “The Ecumenical Movement in Asia: A Theological Reflection" dalam CTC Bulletin, Vol. XXII, No. 3, Desember 2006.

Shastri, Hermen "The Unity of the Church in a Changing World: An Asian Perspective" dalam The Ecumenical Review, Vo. 66.No. 1, 2014.

Song, C. S., "The Ecumenical Calling of the Christian Church today: Ecumenism and Paradigm-Shifts" dalam The Ecumenical Review, vol. 41/1989.

Smit, Peter Ben "The Meaning of LIFE: The Giving of Life as A Criterion for Ecumenical Hermeneutics" dalam Journal of Ecumenical Studies, 43, 2008.

Tabbernee, William "Interpreting the Scriptures Together Seeking the Visible Unity of the Church" dalam Journal of Ecumenical Studies, Vol. 43, No. 3, 2008.

Von Sinner, Rudolf "Ecumenical Hermeneutics for a Plural Christianity and Chatolicity" dalam Bangalore Theological Forum, vol. XXXIV, No. 2, Desember 2002.

Von Sinner, Rudolf "Ecumenical Hermeneutics: Suspicion vs. Coherence" dalam Bangalore Theological Forum, Vol. XXIX. No. 3-4, September-December 1997.

Wang, Kwok Nai "Enchancing Ecumenism and the Ecumenical Movement at the Local Level” dalam CTC Bulletin, vol. XXII, No. 2, August 2006. 